\title{
Characterization of Air Pollution Index and Its Affecting Factors in Industrial Urban Areas in Northeastern China
}

\author{
Jiping Gong ${ }^{1,2}$, Yuanman $\mathrm{Hu}^{1 *}$, Miao Liu' ${ }^{1}$, Rencang Bu${ }^{1}$, \\ Yu Chang ${ }^{1}$, Chunlin $\mathrm{Li}^{1}$, Wen $\mathrm{Wu}^{1,2}$ \\ ${ }^{1}$ State Key Laboratory of Forest and Soil Ecology, Institute of Applied Ecology, Chinese Academy of Sciences, \\ Shenyang 110164, People's Republic of China \\ ${ }^{2}$ University of Chinese Academy of Sciences, \\ Beijing 100049, People's Republic of China
}

Received: 22 December 2014

Accepted: 18 February 2015

\begin{abstract}
The air pollution index (API) and meteorological parameters in four cities (Harbin, Changchun, Shenyang, and Dalian) in northeastern China were analyzed in 2001-12, to study the characterization of the API and its influential factors. According to the monitoring data, air pollution is a significant problem in northeastern China, with all four industrial cities heavily polluted, especially Shenyang. During the study period, the API in the cities was down slightly. Clear interannual, seasonal, and monthly variations of air pollution were determined, which indicated that air quality was poorest in winter (especially November and December), but improved in summer (especially July and August). Air quality level varied in different weather conditions. Water vapor pressure was the most influential meteorological factor with regard to the API, followed by air temperature and surface pressure. Wind direction was found to be an important influential factor with regard to air pollution, because air flow from different directions has an impact on the accumulating or cleaning process of pollutants. However, the dominant meteorological factors influencing air pollution varied in each of the cities in terms of season, time scale, and level of air pollution. Our results highlight the significant impact of synoptic weather on API in northeastern China.
\end{abstract}

Keywords: air pollution index (API), temporal characteristics, wavelet analysis, meteorological factors, northeastern China

\section{Introduction}

Air pollution is a major urban environmental problem. Urban air pollution is a well-documented and widely researched topic because of its great impact on public health, well-being, and the environment, especially in rapidly developing and newly industrialized countries such

*e-mail: huym@iae.ac.cn landscapehym@163.com as China. World Bank research has highlighted that 16 out of the top 20 most air-polluted cities in the world are located in China [1]. The increase in impervious surfaces following urbanization without reasonable urban planning, and increased energy consumption in response to the growth of the urban population in metropolitan regions, exacerbate air pollution [2].

Generally, the causes of air pollution within a region are complex and depend mainly on synoptic patterns and anthropogenic emission densities [3]. In fact, in addition to 
emission sources, meteorological factors such as relative humidity, pressure, wind, and temperature might contribute either directly or indirectly to the level of pollutants within a region, or transport pollutants to other distant regions via complex interactions between various processes over different spatiotemporal scales $[4,5]$. A number of weather elements could exert influence over the variations in levels of air pollution, but previous studies have shown that there is a substantial difference in the capacity for air pollution loading under different synoptic patterns and different regional conditions. Research has revealed that the synoptic pressure pattern and its evolution are important factors behind regional air pollution processes in northern China [6]. However, there are difficulties in establishing direct links between weather parameters and air pollutant concentrations, because the relationship between levels of air pollution and meteorological conditions is complex. Statistical studies based on meteorological data and air pollution monitoring data have confirmed that meteorological conditions affect air pollution in numerous ways, and that there are obvious seasonal, monthly, and weekly variations in concentrations of air pollution associated with meteorological conditions. Wavelet analysis [7, 8], the seasonal-trend decomposition procedure based on loess (STL) $[9,10]$, and ridit analysis [11] have been widely used in trend analysis. Principal component analysis $[12,13]$ and multiple linear regression $[14,15]$ are often employed to analyze the predictive relationship between dependent variables (air pollution monitoring data) and the explanatory variables (meteorological data). Apart from emission sources, the interactions between meteorological conditions and air quality within any particular region can be further complicated by modified aerodynamic roughness and the urban heat island effect. Hence, it is clearly understood that air quality not only depends on emission sources, but also, more crucially, on weather elements with multifaceted characteristics that change over various spatiotemporal scales.
Air pollution in China displays different characteristics in different districts and periods. Statistical studies using meteorological data and air pollution monitoring data have confirmed that air pollutants may be related to meteorological conditions directly, e.g. air cycle, wind, and temperature $[16,17]$, or indirectly, e.g. increase in energy demand for heating in cold seasons or energy consumption on working days [18]. However, the most important role of meteorology is the effect on the dispersion, transformation, and removal of air pollutants from the atmosphere and, finally, the effects of spatial-temporal characteristics and pollution levels of air pollutants.

Many Chinese studies on air pollution and its causes have focused primarily on polluted areas such as the Pearl River Delta region [19], the Yangtze River Delta region [20, 21], and the Beijing-Tianjin-Hebei region [22, 23]. However, few studies on air pollution and the long-term trend of change in air quality have been performed in northeasternern China [24-26]. Nearly one third of the resourcebased cities in China are located in the northeast [24], which is the area in which China's heavy industry is found. Activities in this region are characterized by resourcereliant leading industries including iron/steel, coal, crude oil, machinery, metallurgy, and chemical production [27]. As an energy base and region of heavy industry, northeasternern China plays an important role in the economic development of the entire country. Therefore, there is an urgent need to explore the formation mechanisms, influencing factors, and measures for the mitigation of air pollution. This study focused on the following:

(1) Characterization of temporal variations of the API in four traditional industrial cities in northeasternern China: Harbin, Changchun, Shenyang, and Dalian during 2001-12,

(2) Examination of the correlation between meteorological factors and API. This paper is expected to provide some support for air pollution control improvement in this region.

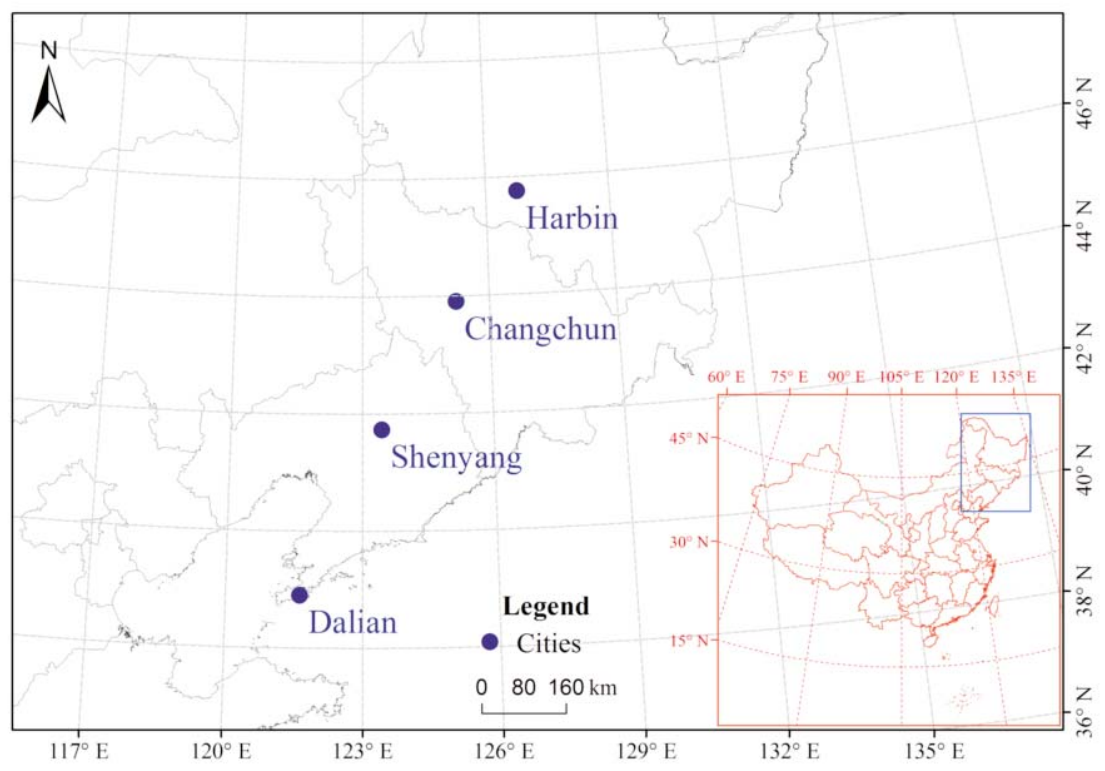

Fig. 1. Location of study area. 


\section{Data and Methods}

\section{Site Distribution}

Northeastern China encompasses three main provinces: Liaoning, Jilin, and Heilongjiang, and the eastern area of Inner Mongolia. In this study, four major industrial cities (Harbin, Changchun, Shenyang, and Dalian) were selected as sample cities, based partly on latitude and their location with respect to the sea. Location and information of the four typical industrial cities examined in this study were shown in Fig. 1 and Table 1. Harbin, Changchun, and Shenyang are within the temperate continental climate zone, located in the Northeastern Plain, they face the Changbai Mountain on the east, the Da Hinggan Mountains on the west, and the Xiao Hinggan Mountains to the north, whereas Dalian is a coastal city, affected by the continental monsoon and ocean climate. All the cities characterized by a long and chilly winter (about five to six month) when coal are heavily used for heating purpose.

\section{Data}

\section{Ambient Air Quality Data}

Currently, only three pollutants are included in the API in China: $\mathrm{SO}_{2}, \mathrm{NO}_{2}$, and $\mathrm{PM}_{10}$. According to new ambient air quality standard by Ministry of Environmental Protection of the People's Republic of China in 2012, $\mathrm{PM}_{2.5}, \mathrm{O}_{3}$, and $\mathrm{CO}$ were added, while API calculation was unchanged. The daily API value for a 12 -year period from 1 January 2001 to 31 December 2012 for the sample cities, API value and pollutant concentrations value from 25 January 2013 to 5 February 2013 in Shenyang were downloaded from the website of the Ministry of Environmental Protection of the People's Republic of China (http://datacenter.mep.gov.cn/).

$$
\begin{gathered}
A P I_{i}=\left(A P I_{U}-A P I_{L}\right) /\left(C_{U}-C_{L}\right) \times\left(C_{i}-C_{L}\right)+A P I_{L} \\
A P I=\max \left(A P I_{i}\right)
\end{gathered}
$$

...where $A P I_{i}$ is the daily index value of each pollutant $i$ (i.e., $\mathrm{SO}_{2}, \mathrm{NO}_{2}$, and $\mathrm{PM}_{10}$ ) in a city, which is first calculated using Eq. (1); $C_{i}$ is the observed concentration of pollu$\operatorname{tant} i ; C_{U}$ and $C_{L}$ represent the break-point concentrations of pollutant $i$ at the lower and upper limits of the API category listed in Table 2 [28], respectively; and $A P I_{U}$ and $A P I_{L}$ are the index values at the lower and upper limits of that API category, respectively. The maximum $A P I_{i}$ value among all the pollutants is then selected as the API of the city, as described by Eq. (2), and the pollutant responsible for the highest index value is the defined as the "main pollutant," if the API is above 50. Meanwhile, Monthly API from 2001 to 2012 of each sample city was calculated to

\begin{tabular}{|c|c|c|c|c|}
\hline 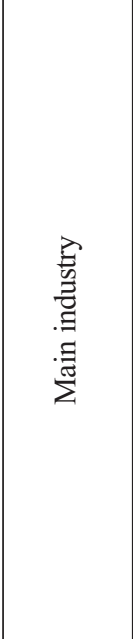 & 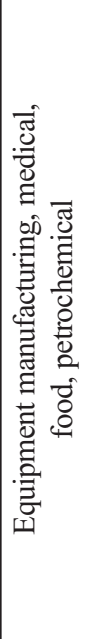 & 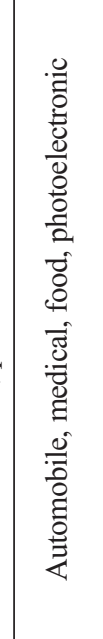 & 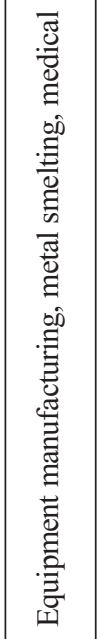 & 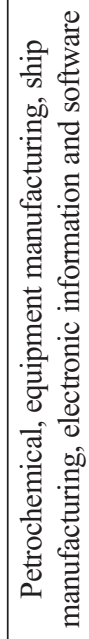 \\
\hline 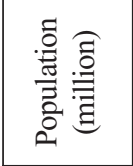 & $\stackrel{\Delta}{\circ}$ & $\stackrel{n}{n}$ & $\stackrel{\sim}{\sim}$ & in \\
\hline 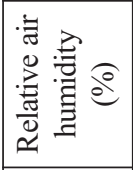 & $\widehat{6}$ & $\beta$ & 8 & రె \\
\hline 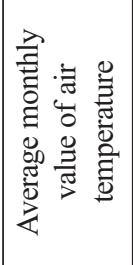 & 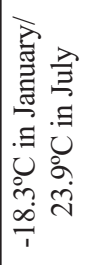 & 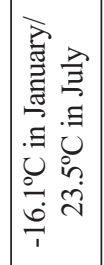 & 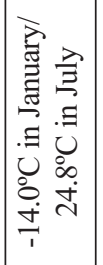 & 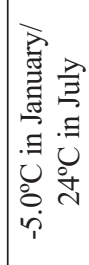 \\
\hline 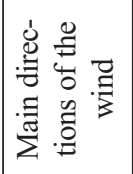 & \multicolumn{4}{|c|}{ 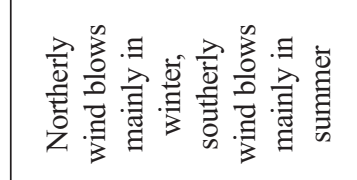 } \\
\hline 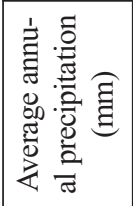 & $\stackrel{\infty}{\stackrel{+}{i}}$ & $\stackrel{m}{\infty}$ & 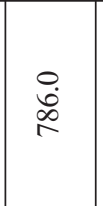 & ڤે̀ \\
\hline 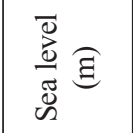 & 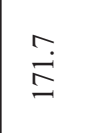 & $\begin{array}{l}\infty \\
\dot{0} \\
\underset{\sim}{0}\end{array}$ & $\begin{array}{l}\stackrel{0}{\vec{q}} \\
\end{array}$ & $\begin{array}{l}\infty \\
\text { a }\end{array}$ \\
\hline 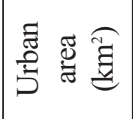 & $\stackrel{\circ}{\circ}$ & $\begin{array}{l}\text { \& } \\
\text { g }\end{array}$ & 衤 & $\frac{n}{d}$ \\
\hline 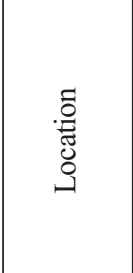 & 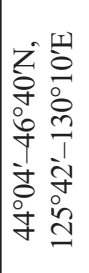 & 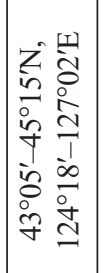 & 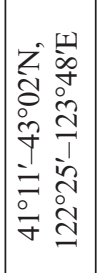 & 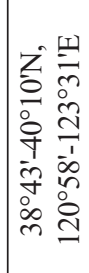 \\
\hline$\stackrel{\nexists}{\partial}$ & 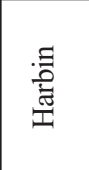 & $\begin{array}{l}\text { 音 } \\
\text { 总 } \\
\text { 志 } \\
\text { 己 }\end{array}$ & 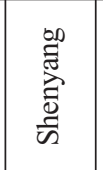 & : \\
\hline
\end{tabular}
analyze its variable trend. 
Table 2. API ranges and corresponding air quality levels.

\begin{tabular}{|c|c|c|c|}
\hline API Category & Air Quality Level & Air Quality & Health Effects \& Health Messages \\
\hline $0-50$ & I & Excellent & \multirow{2}{*}{ No health implications. Enjoy your usual outdoor activities. } \\
\hline $51-100$ & II & Good & \\
\hline $101-150$ & $\mathrm{III}_{1}$ & \multirow{2}{*}{$\begin{array}{l}\text { Slightly } \\
\text { polluted }\end{array}$} & \multirow{2}{*}{$\begin{array}{l}\text { Slight irritation might occur. Members of sensitive groups should reduce } \\
\text { outdoor activities. }\end{array}$} \\
\hline $151-200$ & $\mathrm{III}_{2}$ & & \\
\hline $201-250$ & $\mathrm{IV}_{1}$ & \multirow{2}{*}{$\begin{array}{l}\text { Moderately } \\
\text { polluted }\end{array}$} & \multirow{2}{*}{$\begin{array}{l}\text { Healthy people will be noticeably affected. Children, the elderly, and people with } \\
\text { heart or breathing problems should restrict strenuous outdoor activities. }\end{array}$} \\
\hline $251-300$ & $\mathrm{IV}_{2}$ & & \\
\hline$>300$ & $\mathrm{~V}$ & $\begin{array}{l}\text { Heavily } \\
\text { polluted }\end{array}$ & $\begin{array}{l}\text { Healthy people will experience reduced endurance while performing outdoor activities. } \\
\text { Children, the elderly, and the sick should remain indoors and avoid exercise. } \\
\text { Healthy individuals should avoid outdoor activities. }\end{array}$ \\
\hline
\end{tabular}

Subscripted 1 and 2 - pollution levels.

\section{Meteorological Data}

Daily meteorological data for Harbin, Changchun, Shenyang, and Dalian were obtained from the China Meteorological Data Sharing Service System (http://cdc. cma.gov.cn/), for the same period as the air quality data. They included daily precipitation $(\mathrm{mm})$, average relative humidity $(\%)$, average temperature $\left({ }^{\circ} \mathrm{C}\right)$, average atmospheric pressure $(\mathrm{hPa})$, average water vapor pressure $(\mathrm{hPa})$, average wind speed $(\mathrm{m} / \mathrm{s})$, wind direction, and sunshine duration (h).

\section{Statistical Analysis \\ Seasonal-Trend Decomposition Procedure Based on Loess (STL)}

STL is a filtering procedure for decomposing a time series into additive components of variation (trend, seasonality, and the remainder) by the application of loess smoothing models [29]. The STL method was chosen over other decomposition techniques for this study because it has the important advantage of applicability to a large number of time series [30], which is why it has been widely used in the fields of ecology, environmental science, and meteorology $[9,10,31]$. The STL method was applied to the monthly API time series to analyze its temporal trends, because some components of the API time series produce distortions that hinder the comprehension of their long-term change.

\section{Wavelet Analysis}

The wavelet transform can be applied to analyze a time series that contains non-stationary power at many different frequencies. The Morlet wavelet analysis is especially suited to sinusoidal signals and has been widely used in climate research [8, 32]. In this study, Morlet wavelet analysis was adopted to investigate possible periodic variations of the monthly API for the four sample cities, because air pollution and climatic time series are usually sinusoidal. The sampling period and step were both set to a value of 1 , i.e., 1 month.

\section{Trajectories Calculation}

Recognizing the characteristics of air pollution episode and understanding the causes of these episodes are a prerequisite for authorities and researchers to effectively reduce air pollution. As the worst air pollution city in Northeastern China, Shenyang is listed as the key control city in Liaoning Province by the Ministry of Environmental Protection, it is also the unique key control city in Northeastern China. Take Shenyang for example, we analysis of a heavy pollution episode in Northeastern China. Matrix trajectories were calculated using the Web version of the Hybrid Single Particle Lagrangian Integrated Trajectory model, which is available on the website of the National Oceanic and Atmospheric Administration (NOAA)'s Air Resources Laboratory. The 48-h matrix trajectories were calculated terminating at 0:00 UTC (matrix points $40^{\circ}, 42^{\circ}$, $44^{\circ} \mathrm{N}$ by $120^{\circ}, 122^{\circ}, 124^{\circ}, 124^{\circ} \mathrm{E}$ ) for 24 -h intervals from January 25 to February 5, 2013, at the height of $500 \mathrm{~m}$.

\section{Spearman Rank Correlation Analysis}

Because the API value were not distributed normally, a Spearman's rank correlation coefficient was used to assess the relationships between the daily API and the meteorological data from the sample cities from three perspectives: spatial scales (different cities), temporal scales (seasonal and monthly), and different levels of air pollution.

\section{Results and Discussion}

\section{Spatial Variation}

The statistical characteristics of the five levels of air pollution in the API reveal the distribution of air quality in the sample cities (Fig. 2). During the study period, there were 741 (16.92\%), 306 (6.99\%), 817 (18.66\%), and 185 $(4.22 \%)$ air pollution days in Harbin, Changchun, Shenyang, and Dalian, respectively. The number of polluted days (ranks IV and above) was greatest in Shenyang, then Harbin and Dalian, and the smallest number was in 


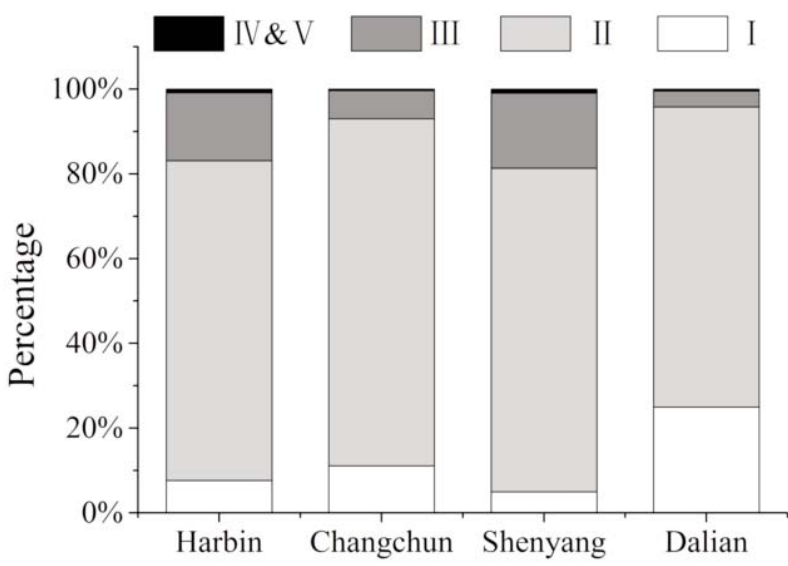

Fig. 2. Distribution of air quality levels in Harbin, Changchun, Shenyang, and Dalian.

Changchun. According to the statistics of the primary pollutants and air pollution days, it was found that $\mathrm{SO}_{2}$ and inhalable particulate matter (PM) had a higher correlation with good or slightly polluted days. In total samples days, $\mathrm{SO}_{2}$ was recorded on $94.64 \%$ and $5.36 \%$ in good and slightly polluted days, respectively, compared with almost none on moderately days and heavily polluted days. Whereas inhalable PM was recorded on $86.14 \%$ in good days, $10.93 \%$ in slightly polluted days, and $2.92 \%$ on moderately days and heavily polluted days, respectively. In addition, inhalable
PM was recorded on $98.99 \%, 88.55 \%, 92.9 \%$, and $80.74 \%$ of polluted days in Harbin, Changchun, Shenyang, and Dalian, respectively. Thus, inhalable PM was deemed the principal air pollutant within the study area.

\section{Temporal Variation}

Fig. 3 presents the results of the decomposition of the seasonal trend of the monthly API in the four sample cities. The original API time series data, shown in the upper layer, were decomposed into the long-term trend, seasonal component, and remainder component. Generally, the monthly API in the sample cities maintains a high level. This phenomenon is partly due to the rapid population growth and economic development, as well as the resulting increased energy consumption. As an established industrial base, Northeastern China remains the area of the country with the worst levels of atmospheric particulates [24]. However, the monthly API in both Harbin and Changchun illustrates an undulating decrease, especially after 2006. The monthly API in Shenyang decreases gradually and the monthly API in Dalian increases prior to 2007, reaching a peak in 2006 and then decreasing. The remainder component is the residuals from the seasonal plus trend fit. It can be seen to have larger variance during the winter and spring months in all four cities (Fig. 3). This finding might be a result of shortterm air pollution episodes for a days in these months. In
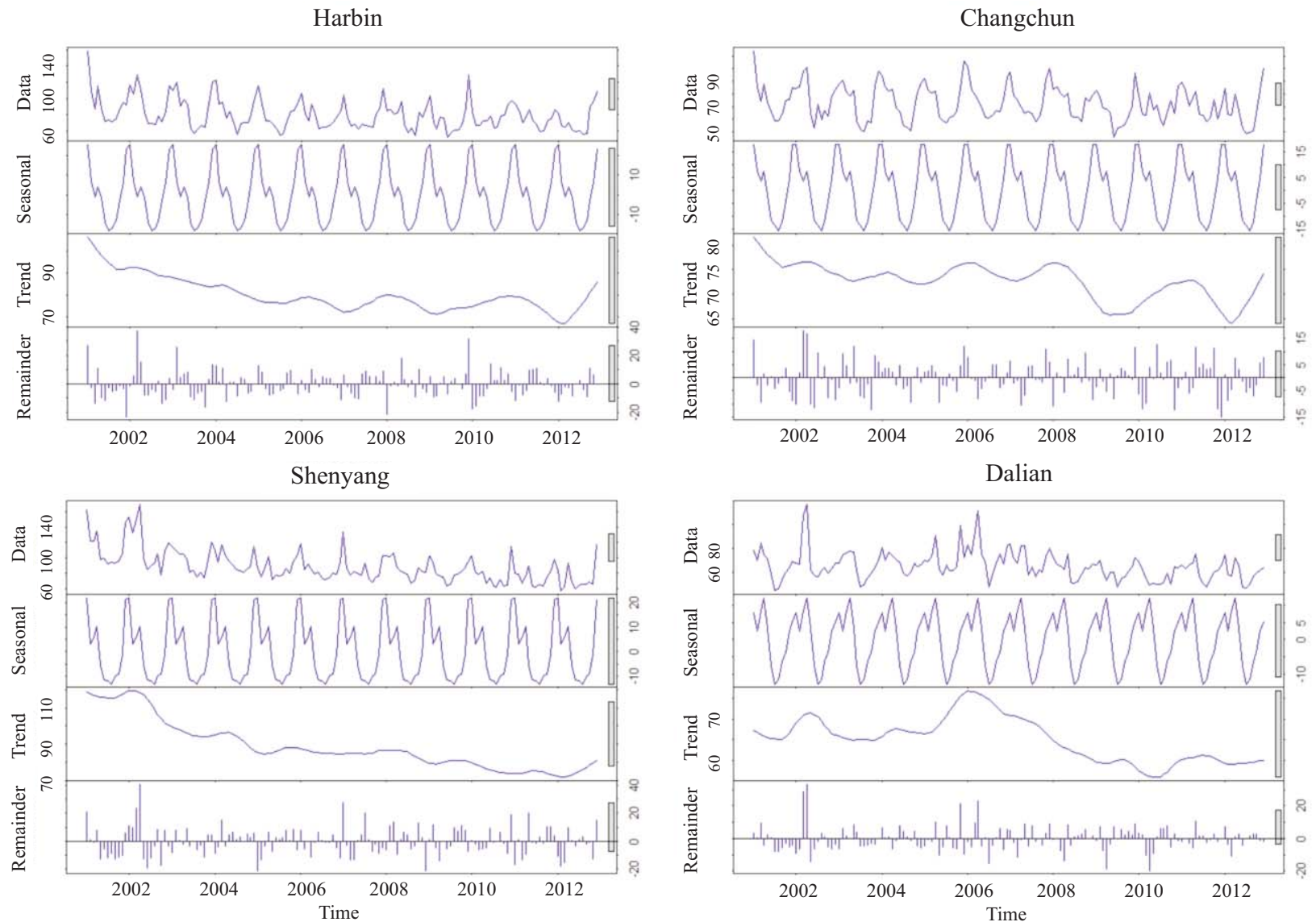

Fig. 3. Decomposition plots of the monthly average API in Harbin, Changchun, Shenyang, and Dalian 2001-12. The upper layer shows the original monthly API time series. The other layers show the decomposed components, i.e., the long-term trend, seasonal, and remainder components, respectively. 
general, air quality in Northeastern China can be seen to improve during the study period. An important reason for this trend was that the municipal governments had adopted a series of legislation and regulation to tackle the serious problem of high concentrations of air pollutants. To improve air quality and keep the environment clean, a variety of activities such as issuing strict emissions standards and developing new and renewable energy resources have been initiated. During 2001 to 2012, excellent air quality occurred on $<30 \%$ of the days in Dalian and $<15 \%$ of the days in the other three cities. Hence, considering the continued growth of the population and economy, the need to improve air quality, through renewed efforts that are more
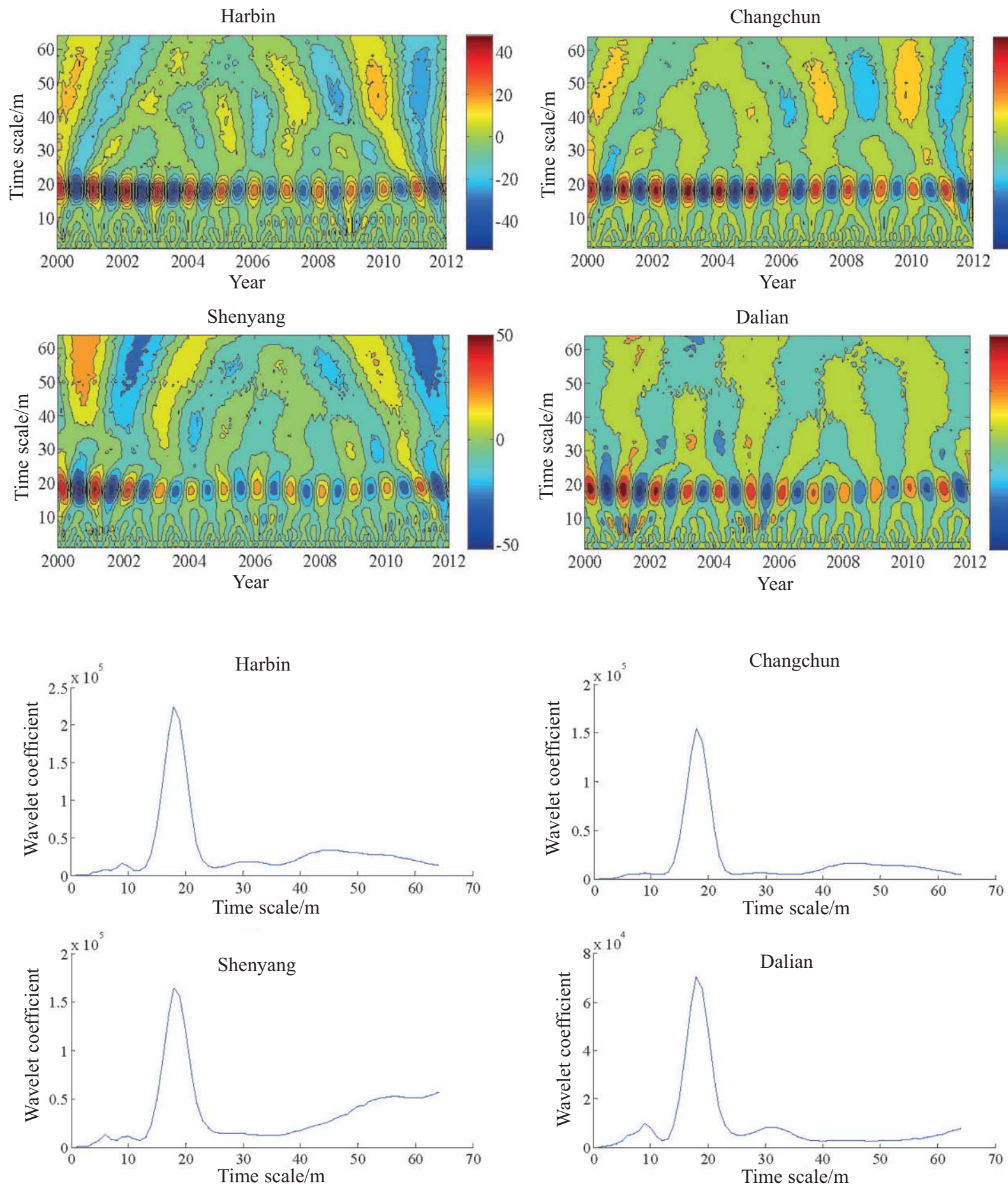

Fig. 4. Morlet wavelet coefficients of monthly API and wavelet variances in Harbin, Changchun, Shenyang, and Dalian. 
signal of the API on smaller spatial scales. The lower the color value, the bigger the wavelet coefficient, and vice versa. We found that the API has an annual cycle with an area of positive value in spring and winter, and an area with negative value in summer and autumn, similar to the results of the decomposition of the STL monthly API. Meanwhile, periodic oscillation with a short time scale can be seen in some years on the lower part of the figure. This informs us that the seasonality of the API might be caused partly by seasonal variations in meteorological factors. However, towards the end of the study period, the variational characteristics of seasonal API in the cities reduce annually, because the pollution source is represented by motor vehicle exhaust emissions and dust, instead of emissions related to winter heating and industrial and mining enterprises.

Wavelet variance analysis was used to explore the main period of API variation in the sample cities. Wavelet variance can reflect the fluctuations and strengths on all kinds of time scale. The value on the time scale for the peak of the wavelet variance line hints at the main period of API variation. The main period of variation in the sample cities is 18 months, although a minor cycle of 9 months can be seen in some years on the wavelet variance line, especially in Dalian (Fig. 4).

Generally, API shown in Fig. 5 presents an obvious monthly pattern with a dominant peak in winter (December-February) and a secondary peak in spring (March-May). Heavily polluted weather occurs during these seasons because of anthropogenic emissions, such as the burning of biomass after the agricultural harvest and burning of coal for heating. Another important reason for this phenomenon was the dry weather due to stable atmospheric stratification. Therefore pollutants were much harder to dilute diffusion and accumulated around land surface. The numbers of air pollution days in the sample cities show inverted V-curve trends (Fig. 6). The API reaches a low point in summer (June-August), probably due to better conditions of diffusion during this period, such as stronger air convective mixing, higher wind speed, and faster vertical exchange. During this period, the strong southerly winds from the ocean appeared in this region facilitated the easy dispersion of pollutants. Furthermore, air pollutants, especially PM, might be reduced considerably by wet removal because of the effect of larger amounts of precipitation [12]. However, as a coastal city, the monthly variations in the API in Dalian were rather small with a dominant peak in April. Generally, the different seasonal patterns of API in the four cities might result from their specific meteorological conditions and the nature of their air pollution.

\section{Matrix Trajectory Analysis: Shenyang as an Example}

As shown in Fig. 7, the 48-h matrix trajectories terminated at $0: 00 \mathrm{UTC}$ (matrix points $40^{\circ}, 42^{\circ}, 44^{\circ} \mathrm{N}$ by $120^{\circ}$, $122^{\circ}, 124^{\circ}, 124^{\circ} \mathrm{E}$ ) for $24-\mathrm{h}$ intervals from 25 January 2013
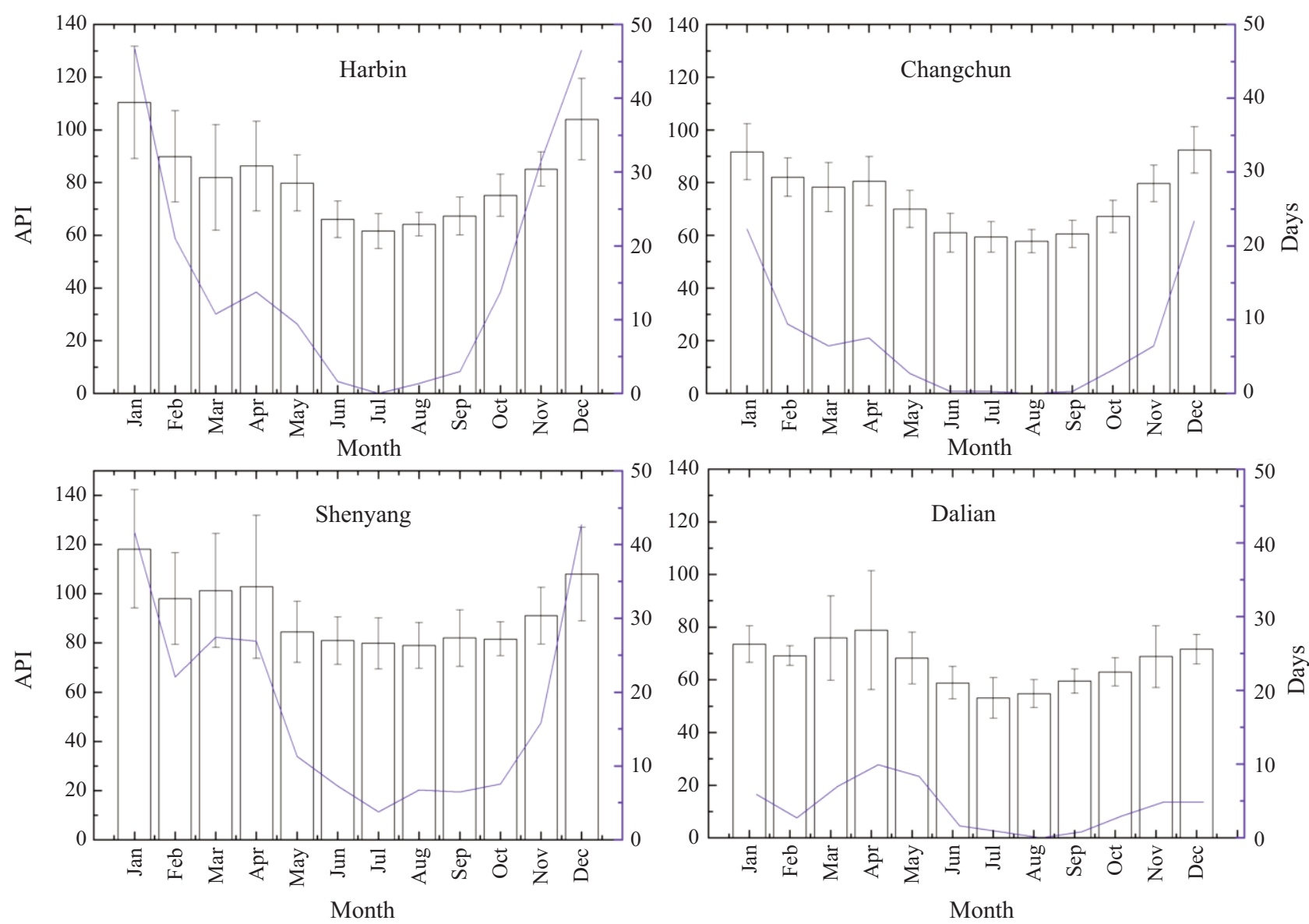

Fig. 5. Monthly mean API, standard deviations, and distribution of air pollution days in Harbin, Changchun, Shenyang, and Dalian. 
to 5 February 2013, at the height of $500 \mathrm{~m}$. It showed two typical "accumulating-to-cleaning" cycles. The air quality got better, while the origins of the back trajectories changed from the north or northwest to the southwest or southeast over a series of days. It has said that pollutants from outside with the winds would endanger air quality through the analysis of the relationship between API and wind direction.

The 48-h matrix trajectories pointed to obvious spatial differences in transport patterns during period. From January 28 to February 1, the origins of the trajectories changed from the northwest to the southeast or southwest. After 4 days of clean air, the directions of the flows in the study areas shifted from the southeast to the northwest. This indicated that another accumulation process had occurred. The origins of the trajectories terminating at $\left(40^{\circ} \mathrm{N}, 122^{\circ} \mathrm{E}\right)$, $\left(40^{\circ} \mathrm{N}, 124^{\circ} \mathrm{E}\right),\left(40^{\circ} \mathrm{N}, 126^{\circ} \mathrm{E}\right),\left(42^{\circ} \mathrm{N}, 124^{\circ} \mathrm{E}\right)$ and $\left(42^{\circ} \mathrm{N}\right.$, $\left.126^{\circ} \mathrm{E}\right)$ among them shifted markedly. In detail, the origins of the trajectories began in the southeast, then shifted to the northwest (February 2), rotated to the southwest (February 4), and returned to the northwest (February 5). The API, meanwhile, throughout the study areas was lower than other days from January 28 to January 31 and February 3 (Table 3). The $\mathrm{SO}_{2}$ was the primary air pollutant, while the origins of the back trajectories changed from the north or northwest to the southwest or southeast, and the air became more humid. The higher humidity could affect the formation of secondary aerosol, such as sulfate and nitrate. Pollutants were mainly local road transport and industrial pollutants caused by man-made emission or the products of photochemical reactions. The primary pollutant in Shenyang was $\mathrm{PM}_{2.5}$ in heavily polluted days, while the origins of the back trajectories changed from the southwest or southeast to the north or northwest over a series of days, and the air became drier. The flows originated from Mongolian Plateau which were favorable for the transport and the continuous accumulation of $\mathrm{PM}_{2.5}$, the formation of regional haze and the generation of regional air-pollution episodes.

The cleaning processes associated with the low API were created in part by clean air descending from the southeast and southwest, whereas the accumulation processes associated with the high $\mathrm{PM}_{2.5}$ concentrations were aided by flows from the north or northwest of China.

\section{Relationships between the API and Meteorological Factors}

API usually exhibits a seasonal cycle, but the exact pattern and the underlying causes of seasonal variation can vary on different perspectives. In this study, a Spearman's rank correlation coefficient between the daily API and meteorological data from the sample cities was investigated from three perspectives: spatial scale (different cities), temporal scale (average seasonal and monthly), and different levels of air pollution (Tables 4, 5, and 6, respectively).
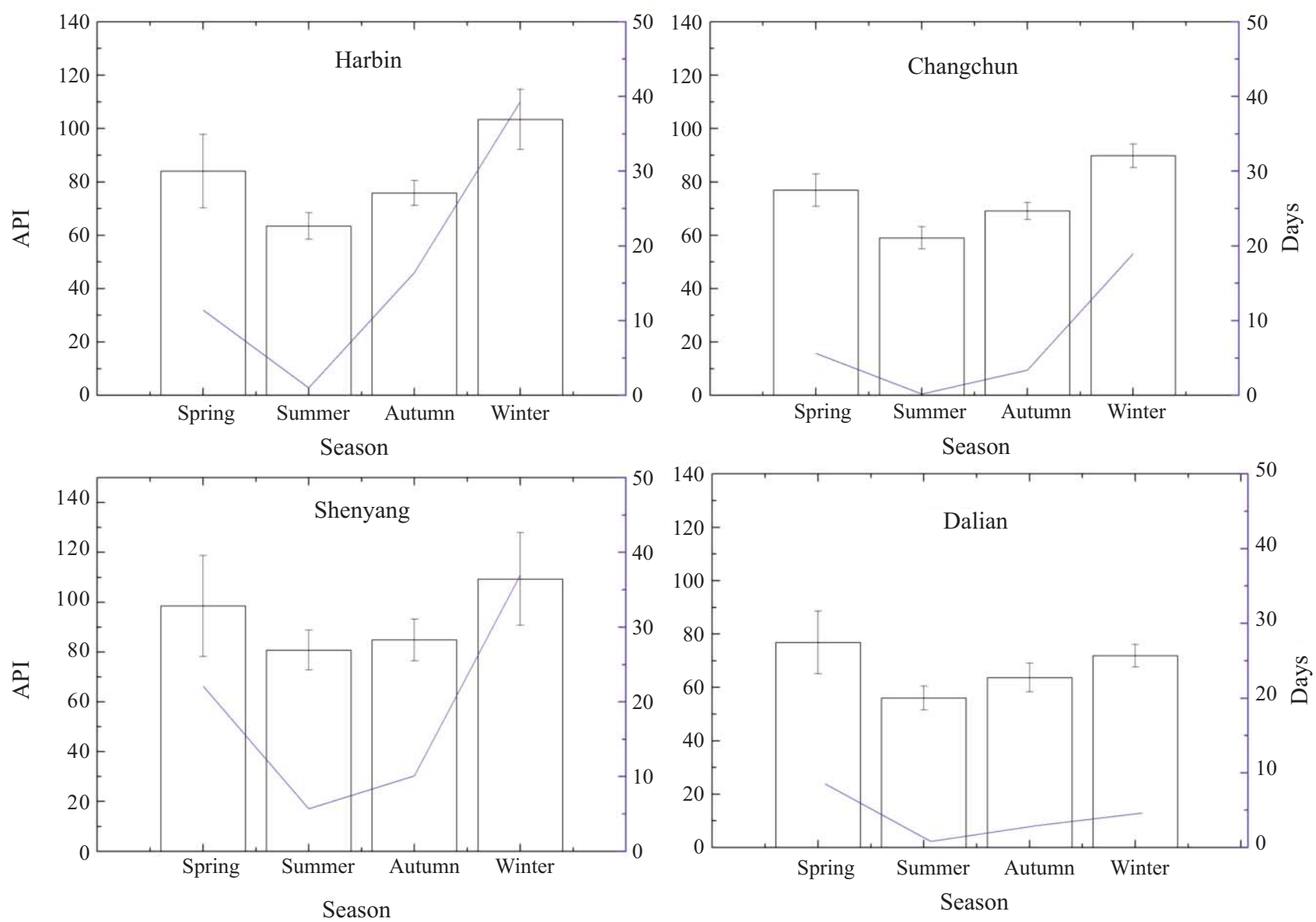

Fig. 6. Seasonal mean API, standard deviations, and distribution of air pollution days in Harbin, Changchun, Shenyang, and Dalian. 


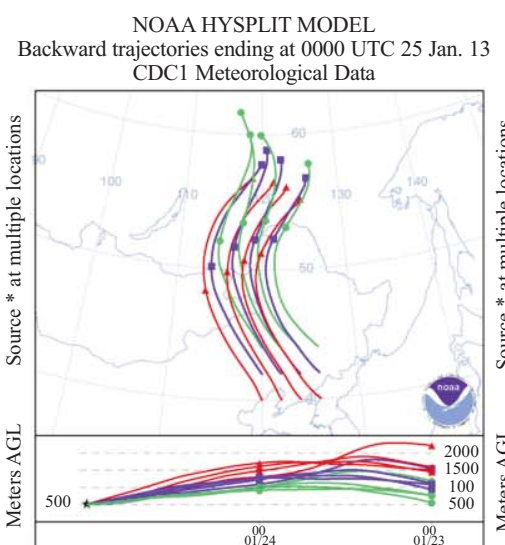

NOAA HYSPLIT MODEL Backward trajectories ending at 0000 UTC 28 Jan. 13 CDC1 Meteorological Data

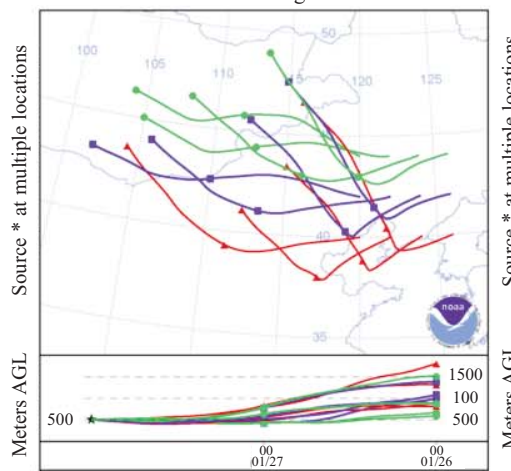

NOAA HYSPLIT MODEL Backward trajectories ending at 0000 UTC 31 Jan. CDC1 Meteorological Data

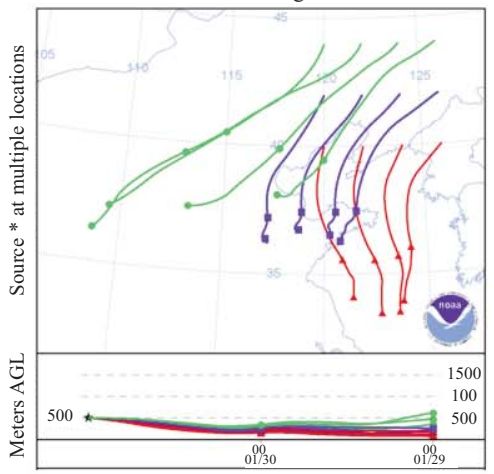

NOAA HYSPLIT MODEL Backward trajectories ending at 0000 UTC 03 Feb. 13 CDC1 Meteorological Data

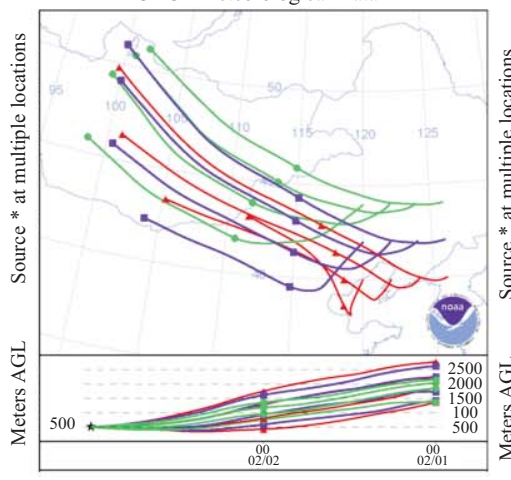

NOAA HYSPLIT MODEL Backward trajectories ending at 0000 UTC 26 Jan. 13 DC1 Meteorological Data

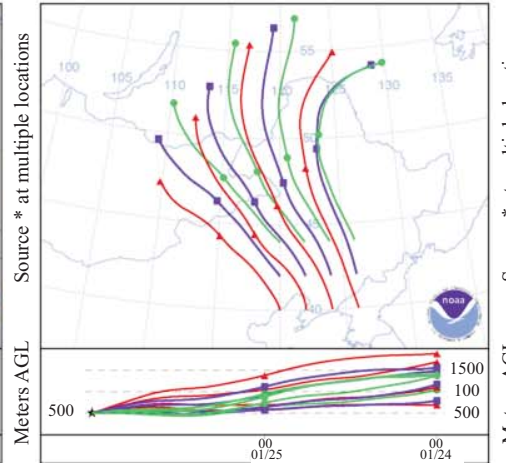

NOAA HYSPLIT MODEL Backward trajectories ending at 0000 UTC 29 Jan. 13 CDC1 Meteorological Data

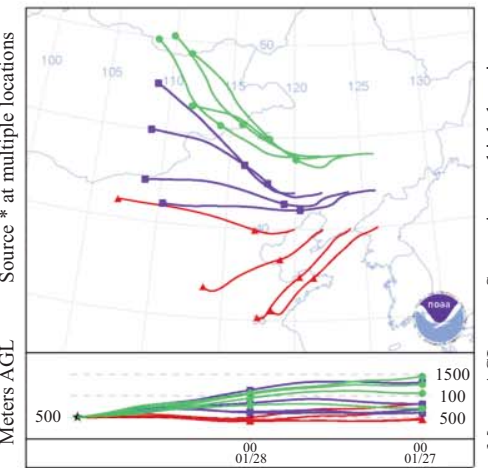

NOAA HYSPLIT MODEL Backward trajectories ending at 0000 UTC $01 \mathrm{Feb}$ CDC1 Meteorological Data

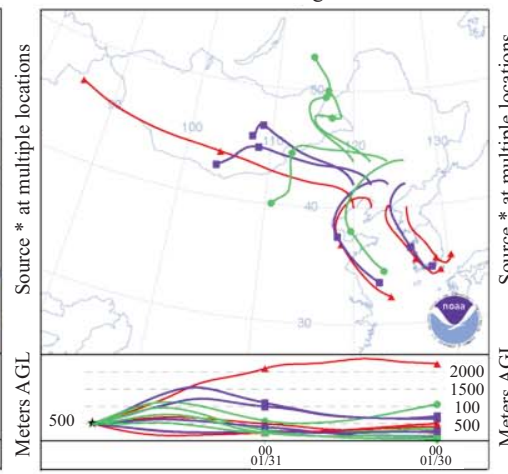

NOAA HYSPLIT MODEL Backward trajectories ending at 0000 UTC
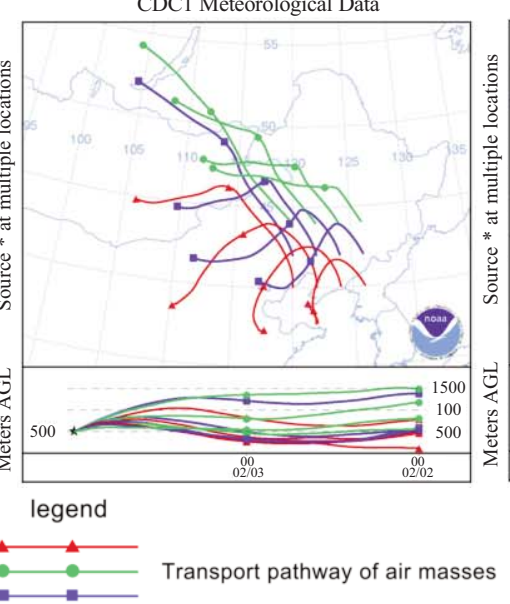

NOAA HYSPLIT MODEL Backward trajectories ending at 0000 UTC 27 Jan. 13 CDC1 Meteorological Data

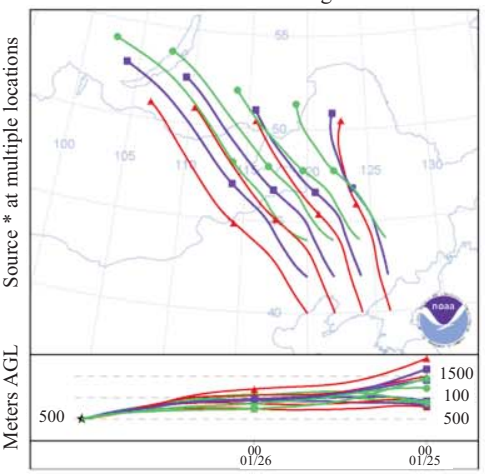

NOAA HYSPLIT MODEL Backward trajectories ending at 0000 UTC 30 Jan. 13 CDC1 Meteorological Data

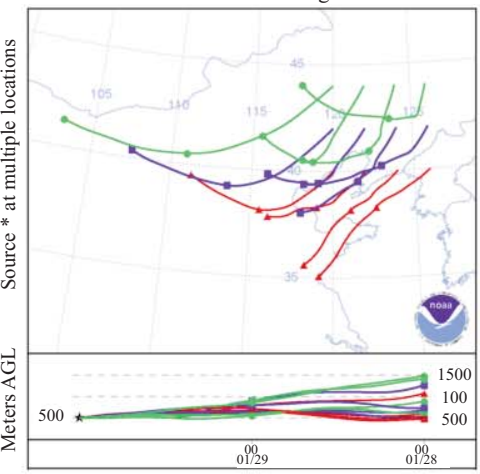

NOAA HYSPLIT MODEL Backward trajectories ending at 0000 UTC 02 Feb. 13 CDC1 Meteorological Data

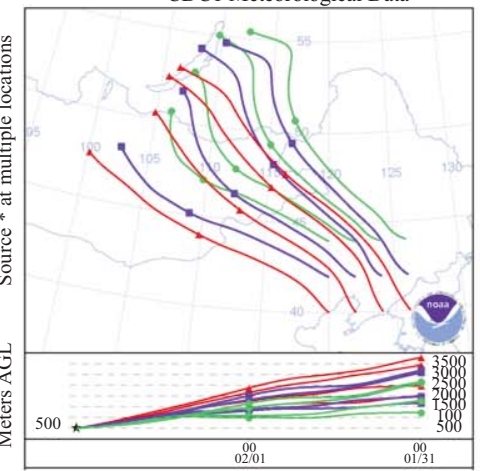

NOAA HYSPLIT MODEL Cectories ending at 0000 UTC 05 Feb. 13 CDC1 Meteorological Data

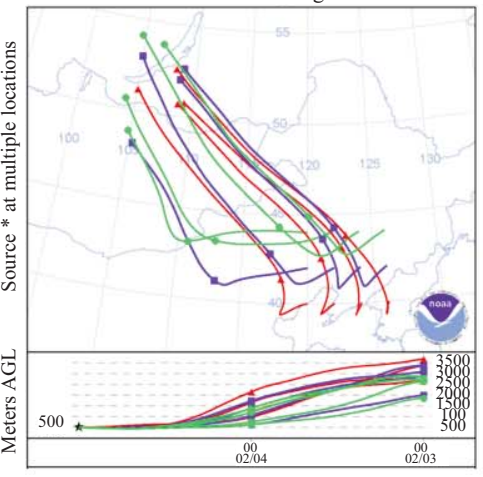

Fig. 7. The 48 -h matrix trajectories (matrix points $40^{\circ}, 42^{\circ}, 44^{\circ} \mathrm{N}$ by $120^{\circ}, 122^{\circ}, 124^{\circ}, 124^{\circ}$ E) terminating at $0: 00$ UTC on January $25-$ February 5, 2013. 
Table 3. Daily API, Primary Pollutant and Air Quality in Shenyang during 25 January 2013 to 5 February 2013.

\begin{tabular}{|c|c|c|c|}
\hline Date & API & $\begin{array}{c}\text { Primary } \\
\text { Pollutant }\end{array}$ & Air Quality \\
\hline $2013-01-25$ & 205 & $\mathrm{PM}_{2.5}$ & Heavily polluted \\
\hline $2013-01-26$ & 232 & $\mathrm{PM}_{2.5}$ & Heavily polluted \\
\hline $2013-01-27$ & 218 & $\mathrm{PM}_{2.5}$ & Heavily polluted \\
\hline $2013-01-28$ & 70 & $\mathrm{SO}_{2}$ & Good \\
\hline $2013-01-29$ & 91 & $\mathrm{SO}_{2}$ & Good \\
\hline $2013-01-30$ & 90 & $\mathrm{SO}_{2}$ & Good \\
\hline $2013-01-31$ & 86 & $\mathrm{SO}_{2}$ & Good \\
\hline $2013-02-01$ & 204 & $\mathrm{PM}_{2.5}$ & Heavily polluted \\
\hline $2013-02-02$ & 104 & $\mathrm{PM}_{2.5}$ & Slightly polluted \\
\hline $2013-02-03$ & 65 & $\mathrm{SO}_{2}$ & Good \\
\hline $2013-02-04$ & 115 & $\mathrm{PM}_{2.5}$ & Slightly polluted \\
\hline $2013-02-05$ & 234 & $\mathrm{PM}_{2.5}$ & Heavily polluted \\
\hline
\end{tabular}

Table 4 presents the Spearman's rank correlation coefficients between the daily API and meteorological factors in sample cities. Generally, it can be seen that the influence of precipitation, air temperature, surface pressure, water vapor pressure, and sunshine duration on the API is significant in all cities. Besides, the impact of wind speed should not be neglected. The maximum value of average wind speed was $120 \mathrm{~m} / \mathrm{s}$ in total samples. Under the condition of average wind speed less than $30 \mathrm{~m} / \mathrm{s}$, the probability of atmospheric pollution was more than $71 \%$ in total polluted days. Due to these cities grew out of geography surrounded by mountain on three sides, where lower wind speed and relatively stable atmospheric structures mean that atmospheric PM can accumulate gradually [33]. In addition, wind direction was found to have a significant correlation with air pollution. The Spearman's rank correlation coefficients between the probability of air pollution days and wind directions is more than $0.8(p<0.01)$ in each sample city(Fig. 8). This is similar to a study undertaken in Beijing [7].

Table 5 illustrates that air pollution is affected differently by the meteorological factors in different seasons. Only the influence of sunshine duration and wind speed on the API is significant in spring. Based on the API value, Wang et al. [34] quantified the magnitude of the effect of air pollution on sunshine hours in China. This study showed that air pollution can reduce sunshine hours to some extent. Due to their composition, aerosols can directly scatter and/or absorb surface solar radiation (direct radiative forcing). Also as cloud condensation nuclei, aerosols can indirectly affect surface solar radiation by altering the number of droplet condensation and cloudiness (the first and second indirect radiative forcings) [34] which corresponds to the poorest air quality in winter and spring. In summer, which has the best air quality, the air temperature and atmospheric pressure positively affect the API, while precipitation and wind speed have a negative effect. Average surface pressure is the dominant meteorological factors in summer. In general, when an area is controlled by a high atmospheric pressure system, the air mass in the vertical direction will sink to the ground, making the diffusion of air pollutants comparatively difficult. In Northeastern China, average surface pressure varied slightly with seasons, since the atmospheric pressure on the surface in summer (Standard Deviation $=94.03$ ) is fairly constant than spring (Standard Deviation=112.25), autumn (Standard Deviation=104.09) and winter (Standard Deviation=115.91) throughout the study period, the cross correlation between API and atmospheric pressure is persistent, followed by autumn. Precipitation, atmospheric pressure, and wind speed are the dominant meteorological factors in autumn. In winter, with the poorest air quality, relative humidity positively affects the API, while air temperature, water vapor pressure, wind

Table 4. Relationship between daily API and meteorological factors in sample cities.

\begin{tabular}{|c|c|c|c|c|c|c|c|c|c|}
\hline & & PRCP & RHU & TEM & PRS & WVP & WS & SD & \\
\hline \multirow{8}{*}{ API } & Correlation Coefficient & $-0.169 * *$ & -0.021 & $-0.365^{* *}$ & $0.328^{* *}$ & $-0.387 * *$ & $-0.092 * *$ & $-0.212 * *$ & \multirow{2}{*}{ Harbin } \\
\hline & Sig. (2-tailed) & 0 & 0.225 & 0 & 0 & 0 & 0 & 0 & \\
\hline & Correlation Coefficient & $-0.202 * *$ & $-0.155^{* *}$ & $-0.426 * *$ & $0.380^{* *}$ & $-0.466 * *$ & $-0.023 * *$ & $-0.144 * *$ & \multirow{2}{*}{ Changchun } \\
\hline & Sig. (2-tailed) & 0 & 0 & 0 & 0 & 0 & 0.008 & 0 & \\
\hline & Correlation Coefficient & $-0.193 * *$ & $-0.129 * *$ & $-0.234 * *$ & $0.224^{* *}$ & $-0.274 * *$ & $-0.101 * *$ & $-0.094 * *$ & \multirow{2}{*}{ Shenyang } \\
\hline & Sig. (2-tailed) & 0 & 0 & 0 & 0 & 0 & 0 & 0 & \\
\hline & Correlation Coefficient & $-0.249 * *$ & $-0.265^{* *}$ & $-0.199 * *$ & $0.181^{* *}$ & $-0.264 * *$ & $-0.060 * *$ & $0.049^{* *}$ & \multirow{2}{*}{ Dalian } \\
\hline & Sig. (2-tailed) & 0 & 0 & 0 & 0 & 0 & 0 & 0.004 & \\
\hline
\end{tabular}

* Correlation is significant at the 0.05 level (2-tailed),

** Correlation is significant at the 0.01 level (2-tailed). Sig. is concomitant probability.

PRCP - daily precipitation, RHU - average relative humidity, TEM - average temperature, PRS - average surface pressure, WVP average water vapor pressure, WS - average wind speed, SD - sunshine duration, Sig. - concomitant probability. 
Table 5. Relationship between the daily API and meteorological factors by season.

\begin{tabular}{|c|c|c|c|c|c|c|c|c|c|}
\hline & & PRCP & RHU & TEM & PRS & WVP & WS & SD & \\
\hline \multirow{8}{*}{ API } & Correlation Coefficient & 0.075 & -0.205 & 0.216 & 0.261 & 0.019 & $-0.063 * *$ & $-0.331 *$ & \multirow{2}{*}{ Spring } \\
\hline & Sig. (2-tailed) & 0.663 & 0.229 & 0.206 & 0.124 & 0.913 & 0 & 0.049 & \\
\hline & Correlation Coefficient & $-0.440 * *$ & -0.327 & $0.447 * *$ & $0.504 * *$ & -0.022 & $-0.419 *$ & -0.092 & \multirow{2}{*}{ Summer } \\
\hline & Sig. (2-tailed) & 0.007 & 0.052 & 0.006 & 0.002 & 0.900 & 0.011 & 0.593 & \\
\hline & Correlation Coefficient & $-0.371 *$ & -0.069 & -0.269 & $0.409 *$ & -0.246 & $-0.583 * *$ & -0.091 & \multirow{2}{*}{ Autumn } \\
\hline & Sig. (2-tailed) & 0.026 & 0.688 & 0.112 & 0.013 & 0.149 & 0 & 0.597 & \\
\hline & Correlation Coefficient & -0.152 & $0.617 * *$ & $-0.545^{* *}$ & 0.135 & $-0.453 * *$ & $-0.657 * *$ & $-0.650 * *$ & \multirow{2}{*}{ Winter } \\
\hline & Sig. (2-tailed) & 0.377 & 0 & 0.001 & 0.432 & 0.006 & 0 & 0 & \\
\hline
\end{tabular}

*Correlation is significant at the 0.05 level (2-tailed),

** Correlation is significant at the 0.01 level (2-tailed). Sig. is concomitant probability.

Abbreviations the same as in Table 4.

Table 6. Relationship between the daily API and meteorological factors for different atmospheric pollution levels.

\begin{tabular}{|c|c|c|c|c|c|c|c|c|c|}
\hline & & PRCP & RHU & TEM & PRS & WVP & WS & $\mathrm{SD}$ & \\
\hline \multirow{8}{*}{ API } & Correlation Coefficient & $-0.185 * *$ & $-0.125 * *$ & $-0.294 * *$ & $0.259 * *$ & $-0.332 * *$ & $-0.147 * *$ & $-0.120 * *$ & \multirow{2}{*}{ Total } \\
\hline & Sig. (2-tailed) & 0 & 0 & 0 & 0 & 0 & 0 & 0 & \\
\hline & Correlation Coefficient & $-0.181 * *$ & $-0.160 * *$ & $-0.199 * *$ & $0.204 * *$ & $-0.252 * *$ & $-0.108 * *$ & $-0.048 * *$ & \multirow{2}{*}{$\begin{array}{c}\text { Total I and } \\
\text { II }\end{array}$} \\
\hline & Sig. (2-tailed) & 0 & 0 & 0 & 0 & 0 & 0 & 0 & \\
\hline & Correlation Coefficient & $-0.068 * *$ & $0.087 * *$ & $-0.157 * *$ & $0.225^{* *}$ & $-0.148 * *$ & $-0.137 * *$ & $-0.127 * *$ & \multirow{2}{*}{ Total III } \\
\hline & Sig. (2-tailed) & 0.006 & 0 & 0 & 0 & 0 & 0 & 0 & \\
\hline & Correlation Coefficient & 0.074 & $-0.350 * *$ & $0.454^{* *}$ & $-0.295 * *$ & $0.355^{* *}$ & $0.377^{* *}$ & $-0.159 * *$ & \multirow{2}{*}{$\begin{array}{c}\text { Total IV } \\
\text { and V }\end{array}$} \\
\hline & Sig. (2-tailed) & 0.461 & 0 & 0 & 0.003 & 0 & 0 & 0 & \\
\hline
\end{tabular}

* Correlation is significant at the 0.05 level (2-tailed),

** Correlation is significant at the 0.01 level (2-tailed). Sig. is concomitant probability.

Abbreviations the same as in Table 4.

speed, and sunshine duration have negative effects. The average wind speed is lower in summer $(25.57 \mathrm{~m} / \mathrm{s})$, autumn $(27.84 \mathrm{~m} / \mathrm{s})$ and winter $(27.83 \mathrm{~m} / \mathrm{s})$ than spring $(34.08 \mathrm{~m} / \mathrm{s})$, which was conducive to dispersing the pollutants in the air. However, if the wind speed increased continuously, high probability of pollutants from outside with the winds would endanger air quality. In general, the influence of wind speed on the API is most significant during the seasons with the poorest air quality, while the other meteorological factors have an effect on air pollution in other seasons.

The Spearman's rank correlation coefficients between the daily API and meteorological factors in different air pollution levels were analyzed, because the eigenvalues of the API processed in average and meteorological data tend to be smoother, aiding the description of their correlations (Table 6). We found that air temperature, surface pressure, water vapor pressure, and wind speed are the main factors in the different levels of air pollution. There are no distinct differences among the various air pollution levels. On heavily polluted days, there was no significant correlation between daily precipitation and API due to less precipitation days, especially in spring and wnter. Heating and transport are the major anthropogenic polluting activities during winter in Northeastern China, although contributions from external pollution sources cannot be neglected.

\section{Conclusions}

Within the scope of this study, the following conclusions can be drawn: Shenyang was established as the most seriously air-polluted city in study area. However, the undulating decrease in the API showed that during the study period, air quality in Northeastern China improved. The air quality was best in summer, followed by autumn, and poorest in winter and spring. Specifically, air quality was poorest in November and December, followed by March and April, and best in July and August.

The influences of meteorological factors, including wind direction, water vapor pressure, air temperature and surface pressure were the most important meteorological factor. 

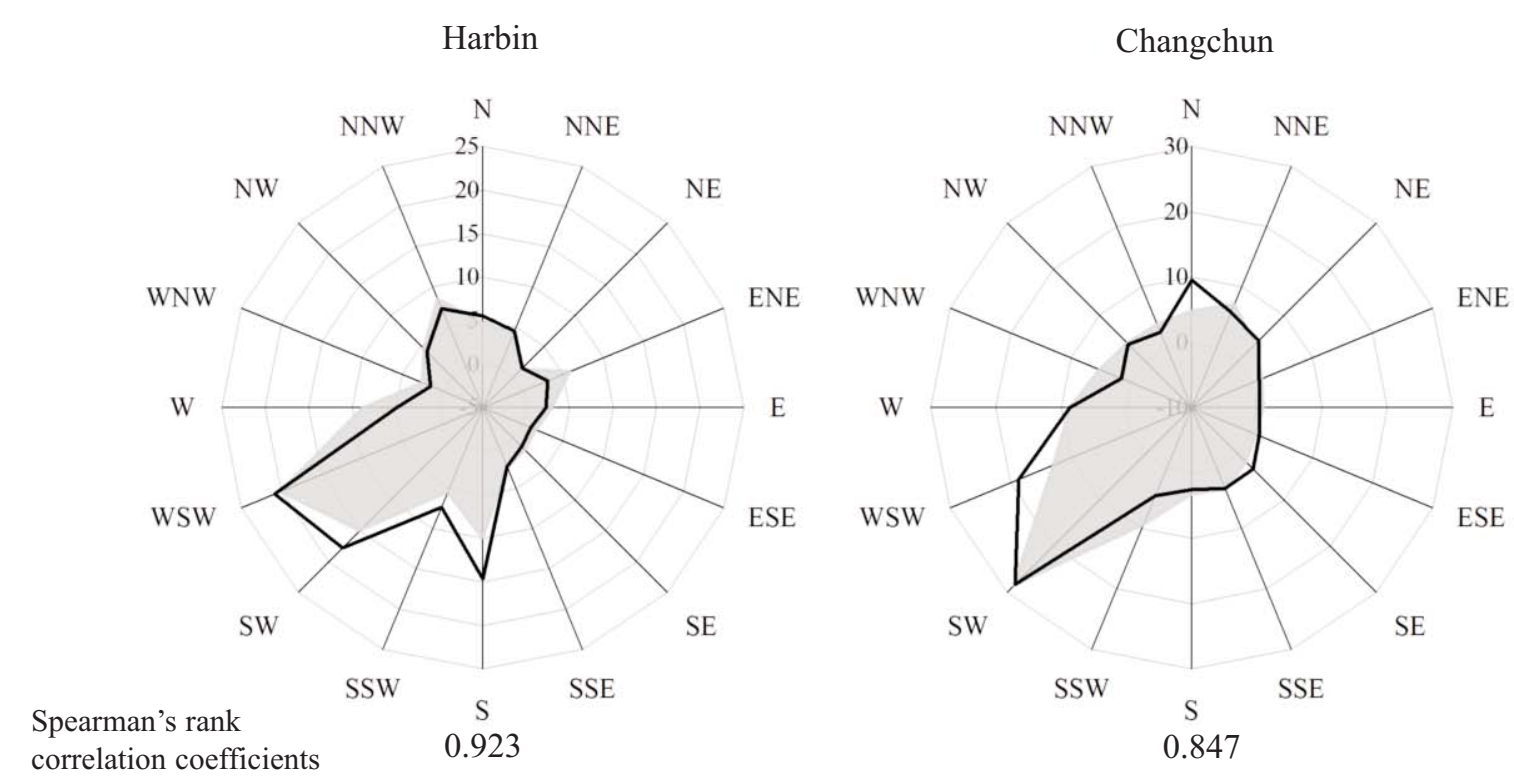

Shenyang

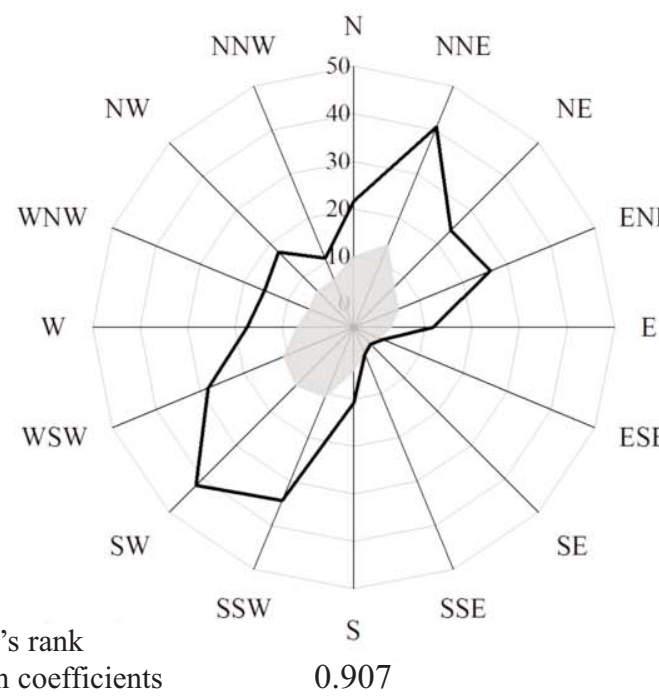

correlation coefficients

0.907

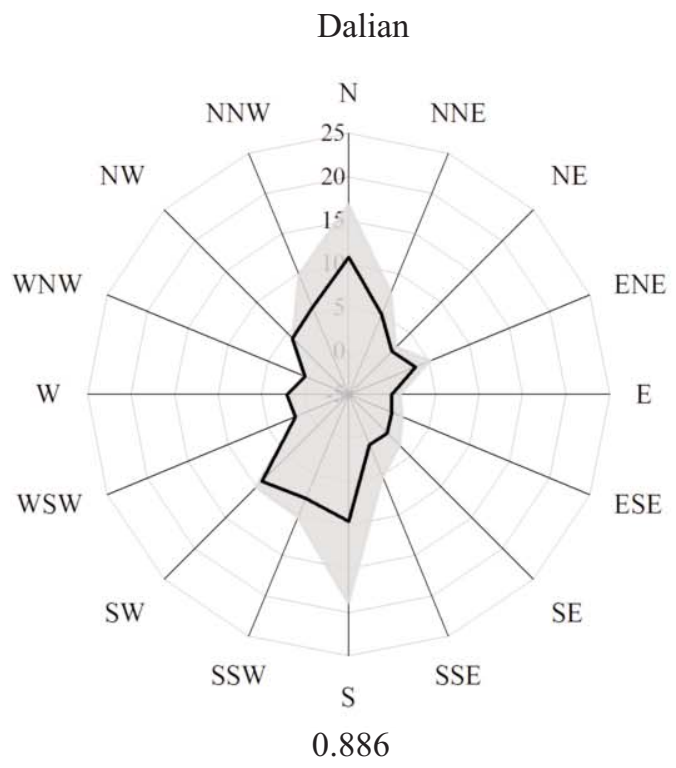

Percentage of wind direction

Percentage of air polluted days

Fig. 8. Probability of air pollution days under conditions of different wind directions and their Spearman's rank correlation coefficients.

However, the dominant meteorological factors influencing air pollution varied with the season. Only sunshine duration and wind speed had a significant influence on the API in spring. The influence of atmospheric pressure on the API was most significant in summer. Wind speed was the dominant meteorological factor in both autumn and winter. It is quite clear that ensuring ventilation may reduce pollution. Furthermore, precipitation, temperature, surface pressure, and water vapor pressure were the important meteorological factors influencing the API in cities. In addition, there are no distinct differences among the various air pollution levels. Flows direction was found to have an important influence on air pollution. The Matrix trajectory analy- sis result cites the main sources of $\mathrm{PM}_{2.5}$ of particular high $\mathrm{PM}_{2.5}$ issues in Northeastern China may transpot from Mongolian Plateau. Therefore, attentions should be paid to prevent external pollutant in order to improve the air quality in strong north or northwest windy weather. The local emission sources of $\mathrm{SO}_{2}$ should not be neglected. The matrix trajectories could reasonably explain the relationship between API and wind direction in Northeastern China during the study period.

It is recognized that this study has several limitations. First, the study period was based on a 12-year data set from 2001 to 2012, which might be too short for the realistic exploration of long-term trends in air quality. Second, addi- 
tional data on specific air pollutants such as $\mathrm{SO}_{2}, \mathrm{NO}_{2}$, $\mathrm{PM}_{10}$, and other air pollutants are required to evaluate fully the impacts of air pollution, because these air pollutants are critical to the API. Third, interrelations between meteorological factors were neglected. Further studies on the interrelation and mechanisms of the meteorological factors are needed to verify whether such relationships are concomitant or causal. Air pollution is not only affected by meteorological factors, but also by pollutant emissions, urban landscape pattern and so on. The mechanisms between pollutants and meteorological factors are beyond the scope of this study, as these are complex issues that require specific investigation.

\section{Acknowledgements}

This research was co-funded by the National Natural Science Foundation of China (No. 41171155 and No. 41371198).

\section{References}

1. LOPEZ R. E., THOMAS V., WANG Y. The quality of growth: fiscal policies for better results. The World Bank, Washington, DC, 2008.

2. HARLAN S. L., RUDDELL D. M. Climate change and health in cities: impacts of heat and air pollution and potential co-benefits from mitigation and adaptation. Current Opinion in Environmental Sustainability, 3, 126, 2011.

3. JI D. S., WANG Y. S., WANG L. L., CHEN L. F., HU B., TANG G. Q., XIN J. Y., SONG T., WEN T. X., SUN Y. Analysis of heavy pollution episodes in selected cities of northern China. Atmos. Environ., 50, 338, 2012.

4. DEMUZERE M., TRIGO R. M., VILA-GUERAU DE ARELLANO J., VAN LIPZIG N. P. M. The impact of weather and atmospheric circulation on $\mathrm{O}_{3}$ and $\mathrm{PM}_{10}$ levels at a rural mid-latitude site. Atmos. Chem. Phys., 9, 2695, 2009.

5. JUNENG L., LATIF M. T., TANGANG F. Factors influencing the variations of $\mathrm{PM}_{10}$ aerosol dust in Klang Valley, Malaysia during the summer. Atmos. Environ., 45, 4370, 2011.

6. CHEN Z. H., CHENG S. Y., LI J. B., GUO X. R., WANG W. H., CHEN D. S. Relationship between atmospheric pollution processes and synoptic pressure patterns in northern China. Atmos. Environ., 42, 6078, 2008.

7. TIAN G. J., QIAO Z., XU X. L. Characteristics of particulate matter $\left(\mathrm{PM}_{10}\right)$ and its relationship with meteorological factors during 2001-2012 in Beijing. Environ. Pollut., 192, 266, 2014

8. NALLEY D., ADAMOWSKI J., KHALIL B., OZGAZIELINSKI B. Trend detection in surface air temperature in Ontario and Quebec, Canada during 1967-2006 using the discrete wavelet transform. Atmos. Res., 132, 375, 2013.

9. LI L., QIAN J., OU C. Q., ZHOU Y. X., GUO C., GUO Y. Spatial and temporal analysis of Air Pollution Index and its timescale-dependent relationship with meteorological factors in Guangzhou, China, 2001-2011. Environ. Pollut., 190, 75, 2014.
10. MASIOL M., AGOSTINELLI C., FORMENTON G., TARABOTTI E., PAVONI B. Thirteen years of air pollution hourly monitoring in a large city: Potential sources, trends, cycles and effects of car-free days. Sci. Total Environ., 494, 84, 2014.

11. CHEN Y., XIE S. D. Temporal and spatial visibility trends in the Sichuan Basin, China, 1973 to 2010. Atmos. Res., 112, $25,2012$.

12. DENG J. J., WANG T. J., JIANG Z. Q., XIE M., ZHANG R. J., HUANG X. X., ZHU J. L. Characterization of visibility and its affecting factors over Nanjing, China. Atmos. Res., 101, 681, 2011.

13. DOMINICK D., JUAHIR H., LATIF M. T., ZAIN S. M., ARIS A. Z. Spatial assessment of air quality patterns in Malaysia using multivariate analysis. Atmos. Environ., 60, 172, 2012.

14. BELIS C., CANCELINHA J., DUANE M., FORCINA V., PEDRONI V., PASSARELLA R., TANET G., DOUGLAS K., PIAZZALUNGA A., BOLZACCHINI E. Sources for PM air pollution in the Po Plain, Italy: I. Critical comparison of methods for estimating biomass burning contributions to benzo (a) pyrene. Atmos. Environ., 45, 7266, 2011.

15. LI W., WANG C., WANG H. Q. J., CHEN J. W., YUAN C. Y., LI T. C., WANG W. T., SHEN H. Z., HUANG Y., WANG R. Distribution of atmospheric particulate matter (PM) in rural field, rural village and urban areas of northern China. Environ. Pollut., 185, 134, 2014.

16. JI D., WANG Y., WANG L., CHEN L., HU B., TANG G., XIN J., SONG T., WEN T., SUN Y., PAN Y., LIU Z. Analysis of heavy pollution episodes in selected cities of northern China. Atmos. Environ., 50, 338, 2012.

17. VADREVU K. P., CHOI Y. Wavelet analysis of airborne $\mathrm{CO}_{2}$ measurements and related meteorological parameters over heterogeneous landscapes. Atmos. Res., 102, 77, 2011.

18. LIN Y., QIU X., MA Y., MA J., ZHENG M., SHAO M. Concentrations and spatial distribution of polycyclic aromatic hydrocarbons (PAHs) and nitrated PAHs (NPAHs) in the atmosphere of North China, and the transformation from PAHs to NPAHs. Environ. Pollut., 196, 164, 2015.

19. LI J. F., LU K. D., LV W., LI J., ZHONG L. J., OU Y. B., CHEN D. H., HUANG X., ZHANG Y. H. Fast increasing of surface ozone concentrations in Pearl River Delta characterized by a regional air quality monitoring network during 2006-2011. Journal of Environmental Sciences, 26, 23, 2014.

20. FU X., WANG S. X., ZHAO B., XING J., CHENG Z., LIU H., HAO J. M. Emission inventory of primary pollutants and chemical speciation in 2010 for the Yangtze River Delta region, China. Atmos. Environ., 70, 39, 2013.

21. LIAO J. B., WANG T. J., WANG X. M., XIE M., JIANG Z. Q., HUANG X. X., ZHU J. L. Impacts of different urban canopy schemes in WRF/Chem on regional climate and air quality in Yangtze River Delta, China. Atmos. Res., 145, 226, 2014.

22. ZHAO P. S., DONG F., YANG Y. D., HE D., ZHAO X. J., ZHANG W. Z., YAO Q., LIU H. Y. Characteristics of carbonaceous aerosol in the region of Beijing, Tianjin, and Hebei, China. Atmos. Environ., 71, 389, 2013.

23. TANG Y. J., AN J., LI Y., WANG F. Uncertainty in the uptake coefficient for HONO formation on soot and its impacts on concentrations of major chemical components in the BeijingTianjin-Hebei region. Atmos. Environ., 84, 163, 2014.

24. LI W. F., PENG Y., SHI J. W., QIU W. G., WANG J., BAI Z. P. Particulate polycyclic aromatic hydrocarbons in the urban Northeastern Region of China: profiles, distributions and sources. Atmos. Environ., 45, 7664, 2011. 
25. ZHAO H. J., CHE H. Z., ZHANG X. Y., MA Y. J., WANG Y. F., WANG X. X., LIU C., HOU B., CHE H. C. Aerosol optical properties over urban and industrial region of Northeastern China by using ground-based sun-photometer measurement. Atmos. Environ., 75, 270, 2013.

26. JIANG C. M., YU W. T., MA Q., XU Y. G., ZOU H., ZHANG S. C., SHENG W. P. Atmospheric organic nitrogen deposition: Analysis of nationwide data and a case study in Northeastern China. Environ. Pollut., 182, 430, 2013.

27. LI J., YANG W. Y., WANG Z., CHEN H. S., HU B., LI J. J., SUN Y. 1., HUANG Y. A modeling study of source-receptor relationships in atmospheric particulate matter over Northeastern Asia. Atmos. Environ., 91, 40, 2014.

28. State Environmental Protection Administration of China (SEPA). Ambient Air Quality Standard (GB3095-1996), Beijing, China 1996 [In Chinese].

29. CLEVELAND R. B., CLEVELAND W. S., MCRAE J. E., TERPENNING I. STL: A seasonal-trend decomposition procedure based on loess. Journal of Official Statistics, 6, 3, 1990.
30. THEODOSIOU M. Forecasting monthly and quarterly time series using STL decomposition. International Journal of Forecasting, 27, 1178, 2011.

31. GARC A-MOZO H., YAEZEL L., OTEROS J., GAL N C. Statistical approach to the analysis of olive long-term pollen season trends in southern Spain. Sci. Total Environ., 473, 103, 2014.

32. GALIANA-MERINO J. J., PLA C., FERNANDEZCORTES A., CUEZVA S., ORTIZ J., BENAVENTE D. Environmental Wavelet Tool: Continuous and discrete wavelet analysis and filtering for environmental time series. Comput. Phys. Commun., 185, 2758, 2014.

33. HUANG L. K., YUAN C. S., WANG G. Z., WANG K. Chemical characteristics and source apportionment of $\mathrm{PM}_{10}$ during a brown haze episode in Harbin, China. Particuology, 9, 32, 2011.

34. WANG Y., YANG Y., ZHAO N., LIU C., WANG Q. The magnitude of the effect of air pollution on sunshine hours in China. Journal of Geophysical Research: Atmospheres (1984-2012), 117, 1, 2012. 